\title{
Loucuras da fome
}

\author{
Hunger and mental illness
}

Lêda Maria deVargas Rebello 1

1 Departamento de Ciências Sociais em Saúde, Escola Nacional de Saúde Pública, Fundação Oswaldo Cruz. Rua Leopoldo Bulhões 1480, 80 andar, Rio de Janeiro, RJ 21041-210, Brasil.
A bstract Based on a recently-published article on the triad of drought, hunger, and mental illness, in which the main idea is that destitution may beleading to behavioral disorders in the drought-plagued population of the Brazilian Northeast, we reflect on what this so-called "madness" may represent for this group of people. We attempt to analyze the issue from various disciplinary perspectives, going beyond merely causal explanations and taking into account that the reported disorders entail meanings following the articulation of cognitive, affective, and experiential elements founded on the social and cultural relations of individuals. From this point of view, the respective discourse assumes other interpretations, showing that illness is a singular process of construction.

Key words Hunger; Droughts; Mental Health

Resumo Com base em uma reportagem publicada recentemente sobre a tríade seca/fome/doença mental, cuja idéia central é a de que a mi séria decorrente possa estar provocando distúrbios comportamentais na população nordestina atingida, buscamos refletir sobre o que essa suposta 'Ioucura' poderia estar representando para esse grupo de pessoas. Procuramos fazer uma leitura que envolvesse vári as disci pl inas e que ultrapassasse as explicações meramente causais, levando em conta que os transtornos relatados teriam si gnificação a partir da articulação de el ementos cognitivos, afeti vos e experienciais, cal cados nas rel ações soci ais e culturais dos indi ví duos. Nessa perspectiva, o discurso vai assumindo outras interpretações, mostrando que a enfermidade é um processo singular de construção.

Palavras-chave Fome; Secas; Saúde Mental 
A propósito da reportagem Seca efomeacirram distúrbios mentais, publicada na Folha de São Paulo de 31 de maio de 1998 (Guibu, 1998), faremos adiante algumas considerações sobre como vem sendo debatido um problema antigo e conhecido, que volta à cena reforçado pelo alcance dos meios de comunicação. Nesse caso específico, as informações contidas no artigo necessitam de uma reflexão crítica, um "estudo indisciplinado" (Castiel, 1996:27), que fuja dos enquadramentos habituais.

O referido texto toma a dupla questão se$\mathrm{ca} /$ fome, trazendo um terceiro elemento doença mental -, num discurso sustentado por narrativas dramáticas de sertanejos/ trabalhadores rurais. A idéia central éa de que a miséria provocada pela estiagem que atinge o sertão nordestino possa estar modificando o comportamento dessa comunidade, transformando-os nos 'loucos da seca'.

O fenômeno da seca no Nordeste se repete há mais de dois séculos, tendo como conseqüência a miséria, a fome, a doença, a desagregação. Um dos trabalhos de maior alcance sobre essa realidade foi a obra do intel ectual Josué de Castro, que sistematizou um estudo sobre a fome ultrapassando as explicações meramente causais e fisiológicas, refinando o conceito e trazendo à tona “(...) um assunto bastante delicado e perigoso que se constituiu num dos tabus de nossa civilização" (Castro, 1984:13). Segundo Magalhães (1997), o silêncio em torno da fome, como uma questão proibida, ao lado de preconceitos morais, vem escamoteando o debate sobre o quadro da fome e seus contornos. E é dessa fome 'oculta' que, na nossa opinião, trata o artigo.

Segundo a reportagem, moradores da região de Crato (CE) vivenciam uma situação crítica, de absoluta indigência, e estariam apresentando "surtos de desequilíbrio" (Guibu, 1998: 17), com comportamentos violentos e agressivos. Hoje, já se superou, de um ponto de vista sociológico, o enunciado que diz que a miséria produz violência, numa relação biunívoca, linear. Esses parâmetros, segundo Calligaris (1996:5) seguem curvas parecidas com as que descrevem as epidemias, obedecendo ao princípio do tipping point, ou seja, o momento em que o líquido transborda. Esse autor usa como exemplo a garrafinha de ketchup na qual o aumento milimétrico da inclinação pode produzir um dilúvio inesperado, completamente fora de proporção. E, segundo o modelo epidemiológico, uma mudança mínima em um processo aparentemente gradual pode ter o efeito do último milímetro, do 'dilúvio inesperado'. O texto da reportagem aponta para essa 'gota d'água':
“No maior hospital psiquiátrico da região, a Casa de Saúde Santa Tereza, em Crato, sul do Ceará, a procura por atendimento aumentou entre $20 \%$ e $30 \%$ desdeo início do ano, no período da estiagem. Segundo a diretora da instituição, Helenita Santos Telles, uma média de 15 pessoas com supostos problemas mentais procuram atendimento todos os dias no local " (Guibu, 1998:17).

Estamos, então, diante de um tipping point? Que miséria e que fome estão sendo responsabilizadas? De que violência se fala?

Dados oficiais recentes, gerados a partir de um estudo feito em 1993 pelo I pea - Instituto de Pesquisa Econômica Aplicada (Peliano, 1993), revelaram que trinta e dois milhões de brasileiros (mais da quinta parte da população brasileira) defrontam-se diariamente com o problema da fome. E a parcela mais significativa destes é de cerca de 7,2 milhões de indigentes que vivem no Nordeste, com predomínio absoluto na área rural. Apesar dessa constatação, o estudo aponta também para a fome urbana disseminada por todo o território nacional. Cabe atentar para o fato de que não é de hoje que subsiste o problema e o não-enfrentamento efetivo de suas múltiplas causas. Os ciclos da seca têm registro na história oficial e na tradição oral, remontando ao século XVIII. $E$ a fome, decorrência 'natural', tomou um sentido múltiplo num mesmo texto. Tem permanecido presente na agenda do Estado como prioridade pública, sem contudo avançar nas ações implementadas. Por outro lado, alguns movimentos pontuais da sociedade civil foram deflagrados em mobilizações recentes, como a Ação da Cidadania contra a Fome, a Miséria e pela Vida, Iiderada pelo sociólogo Herbert de Souza, o qual falava de uma "cultura da indigência", e que tentou despertar toda a sociedade para o princípio da solidariedade, mostrando o "desi nvestimento cultural na idéia de próximo" (Costa, 1996:8). Essa e outras ações solidárias têm feito emergir uma nova "subj etividade col etiva" (Genro, 1997:3), um 'desvio de percurso', fundamentando uma nova ordem social, preocupada com o atual modelo excludente e com discursos políticos irresponsáveis e programas inoperantes.

Há uma tradição secular em atribuir a causalidade da fome do Nordeste às adversidades do meio ambiente, o chamado mito das intempéries e das catástrofes naturais, em detrimento de análises que façam um desdobramento por outro viés, menos ortodoxo. Para nós importa entender o fenômeno da seca e da fome ultrapassando a mera descrição desse acontecimento. A história de cada entrevistado, ape- 
nas esboçada em curtos depoimentos, ganha a dimensão de uma biografia singular, um caminho revelador para a análise da tríade sugerida: seca/fome/ distúrbio mental, circunscrita numa outra ordem, não biologicista, mas simbólica. Interessa-nos a forma pela qual essas pessoas respondem socialmente à tal situação, e os significados atribuídos a essa experiência. $E$, para que essas experiências tenham uma significação, elas precisam ser interpretadas, tendo como princípio que corpo/mente/ saúde/ doença são objetos de construção social. Ou, como conclui o psiquiatra do hospital da região, Ridalvo Rocha, entrevistado na reportagem, complementando nossas observações: A seca não provoca a loucura (...). A estiagem não éa causa da doença, mas pode ser a gota d'água para que ela se manifeste" (Guibu, 1998:17).

Um outro comentário médico no texto afirma que pessoas com "dieta monótona" (Folha, 1998:18), com deficiência nutricional, podem apresentar um "estado de demência pareci do com a loucura" (Guibu, 1998:18). A nutrição, como processo, implica vários desdobramentos, estabelecendo uma relação ampliada e não reducionista entre homem/ alimento. A loucura, por sua vez, segundo Basaglia (1985), também tem duas faces: a experiência psicopatológica e a condição de exclusão. E o que há em comum entre uma dieta pobre e a loucura? Ambas produzem sofrimento. E por mais que este seja reduzido a uma dimensão biológica e/ ou psicológica, ele existe para o sujeito no seu registro de cidadão. É o sofrimento da exclusão, o sofrimento de quem nada possui (trabalho, moradia, documentos, alimento...), num processo histórico que o separa do cidadão. Ou, retomando o texto da entrevista:

"As pessoas pensam que eu sou louca, mas eu não sou. Sou só revoltada [...] Eu queria comer alface, queijo, cenoura, beterraba, essas coisas que as outras pessoas comem" (Maria Cleonice, 22 anos, entrevistada por Guibu, 1998:17).

Nessa reportagem, temos diante de nós algo como a obra literária de Camus - A Peste (Camus, 1993), que retrata a história de uma cidade subitamente tomada por uma epidemia mortal que se alastra sem encontrar obstácuIos. As reações subjetivas tanto da população, quanto das autoridades, vão construindo a trama. Podemos fazer o paralelo substituindo a peste pela seca, uma realidade dura, injusta, que também 'invade' casas e corpos, lançando o desafio de descobrir a 'medida' subjetiva, os limites de cada um. Resta perguntar: qual é o grau tolerável para resistir?

“Minha casa éfraca, não tem comida, não consigo emprego. Quando eu fico revoltada não vejo nada, sou capaz de fazer qualquer coisa, de esbagaçar tudo." (Maria Cleonice, 22 anos, entrevistada por Guibu, 1998:17).

E o corpo, esse lugar simbólico da loucura, faz o registro das experiências numa operação que não separa linguagem e ação, e que não tem nas coordenadas biológicas a exclusividade das soluções dos impasses. Como afirma Birman (1991:21):

“É preciso consi derar queo corpo simbólico não é del ineado apenas por características inerentes ao desenvol vimento neurofuncional da espécie humana, mas é principal mente construído pelas modalidades de relações sociais que instituem os sujeitos como individualidades e pel os códigos culturais que as comunidades sociais constituem como sujeito, na sua história".

Nessa perspectiva, todo o discurso vai assumindo uma outra interpretação, delineando um campo cheio de indagações, onde cada sujeito tem constituída a marca de sua singularidade, e onde a doença - no caso o tal "estado de demência" (Guibu, 1998:18) - pode assumir um sentido que não corresponda necessariamente às "razões" responsabilizadas no artigo. Assim, deve ser incorporada a compreensão do "sentir-se doente" e "ser considerado doente", modalidades que se situam além da definição de que o indivíduo "tem uma doença” (Castiel, 1994). Ou seja, os episódios de transtornos relatados teriam significação a partir da articulação de elementos cognitivos, afetivos e experienciais, calcados nas relações sociais e culturais desses indivíduos.

Um outro ponto a destacar diz respeito à aquisição de conhecimentos médicos que essas pessoas vão incorporando, em interpretações subjetivas e expressas numa forma socialmente legítima, como o agricultor que teme que a "doença da loucura contagie" (Guibu, 1998:18) toda a família. Esse tema tem sido aprofundado em estudos antropológicos que se referem à arti culação entre as sensações corporais ou mentais e a compreensão de seu significado. Assim, "enquanto interpretação e julgamento, a enfermidade éum processo de construção" (Alves \& Rabelo, 1995:219). Ela existe na medida em que passa a ser aceita como real pelos membros da sociedade.

Considerando-se a expressão 'acirram', retirada do título da matéria - "Seca e fome acirram distúrbios mentais" (Guibu, 1998:17), constatamos como as metáforas midiáticas podem modular o nosso conhecimento dos acontecimentos, nesse caso com objetivo claramente relacional, levando o leitor simplesmente a renovar as metáforas da cultura circundante, for- 
mando uma espécie de névoa que pode deslocar o nosso centro de atenção sobre certos aspectos dos fatos.

Para concluir, resta-nos uma breve reflexão sobre esses comportamentos agressivos que, num sentido figurativo, tentam romper com essa situação perversa de miséria, evitando o conformismo e estabelecendo uma forma de diálogo com a sociedade, uma comunicação simbólica. Quando a filha do agricultor sai "que brando tudo por aí" e "colocando fogo na cerca" (Guibu, 1998:17) torna visível para nós uma atitude de estratégia de 'guerreira' daquilo que se pretendia desviante. No artigo, o depoimento de um cardiologista reforça, de certa maneira, essa idéia:

\section{Referências}

ALVES, P. C. \& RABELO, M. C., 1995. Significação e metáforas: aspectos situacionais no discurso da enfermidade. In: Saúde \& Comunicação: Visibilidades eSilêncios (A. M. R. Pitta, org.), pp. 217-235, São Paulo: Hucitec-Abrasco.

BASAGLIA, F., 1985. A Instituição Negada. Rio de Janeiro: Graal.

BIRM AN, J., 1991. Apresentação: interpretação e representação na saúde coletiva. Physis - Revista de Saúde Coletiva, 1:7-22.

CALLIGARIS, C., 1996. A praga escravagista brasileira. Fol ha deSão Paulo, 22/ 09/96. Caderno Mais!, p. 5. CAMUS, A., 1993. A Peste. Rio de Janeiro: Record.

CASTIEL, L. D., 1994. O Buraco e o Avestruz: a Singularidade do Adoecer Humano. Campinas: Papirus.

CASTIEL, L. D., 1996. Moléculas, Moléstias, Metáforas: o Senso dos Humores. São Paulo: Unimarco.
“Quando o organismo fica sem energia, é ati vado o mecanismo de sobrevivência. O corpo tenta detoda forma lutar e, somado o fator psicossocial, acaba gerando ati tudes agressi vas." (Abrão José Cury J r., médico, entrevistado por Guibu, 1998:18).

Ou, como poeticamente escreve Euclides da Cunha em Os Sertões: “O sertanejo é, antes detudo, um forte" (Cunha, 1979:91). E, de vez em quando, é preciso dar ouvidos à "desrazão" (Costa, 1996:8) e superar o individualismo contemporâneo, a indiferença, a impessoalidade, a atitude de mera contemplação da degradação alheia. Em outras palavras:

“Um grão de loucura e devaneio, quem sabe, é desta fal ta que padecem nossas almas mortas, famintas de encantamento e razão de viver" (Costa, 1996:8).

CASTRO, J., 1984. Geografia da Fome. Rio de Janeiro: Antares.

COSTA, J. F., 1996. A devoração da esperança no próximo. Folha de São Paulo, 22/09/96. Caderno Mais!, p. 8.

CUNHA, E., 1979. Os Sertões. São Paulo: Abril Cultural. GENRO, T., 1997. Uma nova cultura de solidariedade. Fol ha deSão Paulo, 12/ 01/97. Caderno Mais!, p. 3.

GUIBU, F., 1998. Seca e fome acirram distúrbios mentais. Fol ha deSão Paulo, 31/ 05/ 98. 1o caderno, pp. 17-18.

MAGALHÃES, R., 1997. Fome: Uma (Re)Leitura deJosuéde Castro. Rio de Janeiro: Fiocruz.

PELIANO, A. M.T. M., 1993. O Mapa da Fome- Subsídios à Formulação de uma Política de Segurança Alimentar. Ipea, documento. 